$\begin{array}{ll} & \text { Etnográfica } \\ \text { etnográfica } & \text { Revista do Centro em Rede de Investigação em }\end{array}$

Antropologia

vol. 18 (2) | 2014

Vol. $18(2)$

\title{
Os anos 70 em 3D: reflexões pessoais
}

The 1970s in 3D: personal reflections

\section{Brian Juan O'Neill}

\section{(2) OpenEdition \\ Journals}

\section{Edição electrónica}

URL: https://journals.openedition.org/etnografica/3704

DOI: 10.4000/etnografica.3704

ISSN: 2182-2891

\section{Editora}

Centro em Rede de Investigação em Antropologia

\section{Edição impressa}

Data de publição: 1 junho 2014

Paginação: 333-340

ISSN: 0873-6561

\section{Refêrencia eletrónica}

Brian Juan O'Neill, «Os anos 70 em 3D: reflexões pessoais», Etnográfica [Online], vol. 18 (2) | 2014, posto online no dia 09 julho 2014, consultado o 11 fevereiro 2022. URL: http://

journals.openedition.org/etnografica/3704 ; DOI: https://doi.org/10.4000/etnografica.3704

\section{(c) (i) (9)}

Etnográfica is licensed under a Creative Commons Attribution-NonCommercial 4.0 International License. 


\section{Os anos 70 em 3D: reflexões pessoais}

\section{Brian Juan O’Neill}

A década de 1970 começou de facto para o autor em 1968, com os protestos e críticas antiguerra na Universidade de Columbia em Nova Iorque. Refletindo sobre o seu percurso nesse decénio, entreteceram-se três dimensões (a académica, a biográfica e a poética) na sua emigração para a Europa, e na sua passagem dos estudos literários às antropologias americana e britânica. As revelações críticas dos grandes autores realistas tiveram eco no título e no conteúdo da revista londrina Critique of Anthropology, tal como a crítica feroz de etnógrafos como Cutileiro e Bourdieu teve eco na monografia do autor sobre uma aldeia transmontana aparentemente "comunitária", arquiteturada entre 1974 e 1982. A crítica tornou-se um modo de vida. Uma perceção tardia da sua própria identidade étnica dupla de hispânico e "branco assimilado" não descurou a possibilidade de se terem fundido subtilmente todas estas múltiplas dimensões. Podemos acumular duas, senão três, identidades?

PALAVRAS-CHAVE: anos 70, antropologia americana, antropologia britânica, reflexões biográficas, realismo literário, antropologia crítica.

The 1970s in 3D: personal reflections - The 1970s began surprisingly for the author in 1968, amidst anti-war protests and critiques at Columbia University in New York. Pondering over his trajectory during that decade, three dimensions (academic, biographical, and poetic) interlaced as he emigrated to Europe, and as he passed from literary studies through American and later to British anthropology. The critical revelations of the great realists echoed within the title and contents of the London journal Critique of Anthropology, just as the ferocious critical tone of ethnographers such as Cutileiro and Bourdieu echoed within the author's monograph of an apparently "communitarian" hamlet in Trás-os-Montes, composed between 1974 and 1982. Critique became a veritable life-style. Delayed consciousness of his own double ethnic identity as both a Hispanic and an "assimilated white" did not obscure the possibility of all these multiple dimensions having subtly fused together. Can we accumulate two, if not three, identities?

KEYWORDS: 1970s, American anthropology, British anthropology, biographical reflections, literary realism, critical anthropology.

O'NEILL, Brian Juan (bbb.oneill@sapo.pt) - Centro em Rede de Investigação em Antropologia, ISCTE - Instituto Universitário de Lisboa (CRIA-IUL), Portugal. 
INTERPRETEI O CONVITE CORDIAL PARA CONTRIBUIR PARA ESTE DOSSIÊ - talvez erradamente? - de modo totalmente literal: focar a década de 1970 dentro dos seus confins. Assim, estruturei estas brevíssimas linhas à volta de três dimensões, obliquamente entrelaçadas ao longo de 15 anos. Terei de começar esta reflexão dois anos antes de 1970 (em 1968), e acabá-la três anos além do fim (em 1982). As três dimensões, o esqueleto que irá definir a base, são as seguintes: a primeira dimensão (académica) fornece a musculatura, a segunda (biográfica) o sistema sanguíneo, e a terceira (poética e literária) a mentalidade e o Gestalt emocional. Não se trata de uma autobiografia, de um relato de terreno, de "antropologia do umbigo" ou de autoetnografia, mas sim de uma linha da antropologia reflexiva.

Numa primeira fase, entrei na Universidade de Columbia na minha aldeia natal de Manhattan, em Nova Iorque, no outono de 1968, em plenas manifestações contra a guerra do Vietname. Poucos meses antes, no liceu (Horace Mann High School for Boys, em Riverdale, no Bronx), tinha recebido o meu diploma com três colegas no palco da cerimónia, todos nós com bigodes ou barbas, em rebeldia contra a regra, tendo sido avisados para os retirar. Fizemos juramento de nunca o fazer. Note-se que estávamos em junho de 1968, apenas um mês após as explosões estudantis de Columbia, simultâneas com as de Berkeley e Paris. Não sendo ativista pleno, lembro-me de Daniel Cohn-Bendit, e das escadas e entrada do prédio central de Columbia College - Hamilton Hall - cheias de spray-bombs. Após seis anos de inculcação de um espírito crítico académico durante o liceu, confrontei-me com outro nível de crítica, desta vez política e social.

Mas, na dimensão biográfica, olho para o interior desse liceu, onde nós éramos uma meia dúzia de alunos não judeus numa turma de pouco mais de uma centena. Nós - três católicos, dois protestantes e um chinês (de filiação religiosa desconhecida por mim na altura) - éramos os únicos que íamos às aulas nas festas observadas pelos judeus (Jewish holidays). Nalguns momentos, fui chamado de forma pejorativa "spic", uma palavra dirigida por "brancos" a porto-riquenhos (sendo o meu avô paterno dessa ilha, e eu próprio tendo ganho distinções pelas boas notas - honors - em disciplinas de língua espanhola). $\mathrm{Na}$ época, estes subtis insultos à minha costela hispânica ainda não produziam muita consciência, nem repulsa. Porque, parcialmente, já estava assimilado numa faixa do mundo judaico intelectual-artístico da cidade. Lembro-me de tardes passadas no apartamento dum colega, David Steinberg, e de, no elevador do prédio, ter cumprimentado várias vezes a sua vizinha, Barbra Streisand. Mais tarde, como membro da Columbia Student Bartending Agency, servi bebidas em funções, inclusive algumas para Nelson Rockefeller, Margaret Mead e o pintor Mark Rothko.

O primeiro ano da licenciatura foi esquizofrénico. Queria psicologia. Até perceber que as obras do comportamentalista B. F. Skinner (e.g. 1953) dominavam 
o departamento, cujos corredores estavam repletos de pombos. Na cadeira de Introdução à Psicologia, cada aluno tinha um rato, que observámos a beber e a comer. Nos nossos sonhos, os dentes da nossa assistente das aulas práticas pareciam-nos os de um rato gigante. No meio do ano, tive uma hemorragia interna (tipo úlcera), cuja causa atribuí à dificuldade de aguentar a elaboração dos relatórios em gráficos sobre o comportamento dos ratos. A hospitalização ajudou porque o médico escreveu uma carta que me dispensava do serviço militar (dois anos mais tarde, o sistema de recrutamento foi feito por sorteio de datas de aniversários, e fiquei com um número muito alto, tonando-se praticamente impossível ser recrutado). Mas o behaviorismo definitivamente levou-me a abandonar a psicologia a favor da literatura comparada. O meu room-mate, de nome Charlie Yablon, no curso de filosofia, ia lendo O Ser e o Nada de Sartre (1943), fumando um charuto, e olhando para a janela face à Amsterdam Avenue. Dizia: "Brian, eu não sou pessimista, mas otimista, porque acredito que em breve vai acabar o sofrimento humano, após a detonação de uma bomba atómica".

Transitando para a dimensão poética, o meu mergulho na literatura foi feliz. Tive uma cadeira totalmente dedicada à leitura do romance Don Quijote de la Mancha, lido, dissecado e discutido, capítulo por capítulo, entre o nosso grupo de uma dúzia de alunos. Noutras unidades curriculares, li Homero, Rabelais, Melville, Stendhal, Poe, Proust, Frost, Kafka, Twain e Dostoievski (tendo ficado tão fascinado com este que li duas vezes Os Irmãos Karamazov). Conrad era aborrecido, e fazia com que abandonasse, após quatro ou cinco aulas, a cadeira de Modern British Fiction, dada em 1969 por Edward Said, autor nove anos mais tarde do famoso Orientalismo. Apanhei o gosto da escrita, que aliás já se anunciara no liceu, e aprofundei o espírito da desconstrução literária, novamente vivendo a palavra crítica. Fui profundamente influenciado por aqueles professores que transmitiam o entusiasmo pela palavra, a narrativa, a fertilidade do simbolismo da poesia, e o sentido do detalhe e minúcia dos romances realistas, com as suas descrições exaustivas de paisagens, mobília, vestuário, expressões faciais, diálogos e experiências de percursos sociais longos.

Voltemos à biografia: qual o meu futuro como professor de literatura, num país saturado desta disciplina? O meu pai, anteriormente engenheiro/arquiteto do hotel Hilton em Havana em 1957-58, foi transferido no ano seguinte para as ilhas de Trinidad y Tobago, nas Caraíbas, para construir o hotel Hilton na capital desse país, Port of Spain. Vivi um ano no mundo multicultural tão bem retratado por V.S. Naipaul, com a idade de nove anos. De regresso a Nova Iorque em 1960, o meu pai concluiu o doutoramento em $1962 \mathrm{em}$ Columbia, sobre uma escavação arqueológica que tinha elaborado anos antes no México, na década de 1950, com a minha mãe. ${ }^{1}$ Um dos membros do seu 
júri foi Conrad Arensberg, pioneiro dos "estudos de comunidade" na Europa rural (cf. Arensberg 1968 [1937]). Depois ensinava antropologia cultural e arqueologia, no City College da City University of New York. Minha mãe fez a licenciatura em antropologia no Barnard College, da mesma universidade, entre 1942 e 1946. Os meus pais falavam de nomes como Franz Boas, Ralph Linton e Julian Steward. O pai, nos agradecimentos da sua tese, mencionou Alfred Kroeber e Charles Wagley. A mãe teve como professores, entre outros e outras, Margaret Mead, Ruth Benedict e, numa cadeira sobre os índios da América do Sul, Claude Lévi-Strauss. Antes de falecer em 2006, deu-me o seu caderno de notas dessa cadeira. Mas todos estes nomes, quando andava no liceu, não me diziam nada.

Resumindo, com este ambiente familiar como pano de fundo, no segundo e terceiro anos da minha licenciatura, entrava numa espécie de "bigamia disciplinar", porque apanhei uma segunda paixão pela antropologia. Transitei pelo folclore, a sociolinguística e o estruturalismo; os dois primeiros professores da disciplina Introdução à Antropologia foram Robert Murphy (especialista na tribo amazónica dos Mundurucú), e o sinólogo Morton Fried.² Inspirou-me a leitura de Tristes Tropiques de Lévi-Strauss (1967 [1955]) nesta altura, recomendado por Murphy. Desisti duma cadeira dada por Marvin Harris, porque me irritei com as suas aulas no inverno, dadas com óculos de sol. Inscrevi-me na disciplina de Antropologia Visual de Margaret Mead, mas, como ela própria disse na primeira aula que não iria conhecer os trezentos e tal alunos, desisti. Nesta altura, Nina Glick-Schiller estava a acabar o seu doutoramento sobre o Haiti, mas não dei conta de que estava no mesmo departamento. ${ }^{3}$ Conheci Joyce Riegelhaupt muito mais tarde. ${ }^{4}$

Não me desligando da literatura, perfilou-se um futuro mais aventureiro, mais romântico, na antropologia. Ao acabar a licenciatura em 1972, tive de optar entre um doutoramento em literatura em Columbia, Berkeley ou Stanford, ou um mestrado em Sociologia da Literatura, na Universidade de Essex, na Inglaterra. Escolhi a aventura na Europa, nunca mais tendo regressado ao meu país, exceto para curtas visitas.

Ao escrever estas linhas, estou a entrar em pânico. A narrativa alonga-se... e apenas fiquei numa primeira das três fases. Telegraficamente, então, cinco desenvolvimentos posteriores foram os seguintes (onde os níveis académico, biográfico e poético continuam a entrelaçar-se):

1. O livro dos meus pais, de 1972, Open Marriage: A New Lifestyle for Couples, tornou-se um bestseller, traduzido em 14 línguas, e de certa forma

2 Entre os trabalhos destes autores, veja-se, por exemplo, Murphy (1971) ou Fried (1967).

3 Glick-Schiller et al. (1994).

4 Riegelhaupt fez o seu doutoramento sobre Portugal (cf. Riegelhaupt 1964). 
"aplicando" conceitos antropológicos ao casamento norte-americano. ${ }^{5}$ Um aparte: os meus pais já tinham imensos contactos e amizades no mundo artístico-intelectual de Nova Iorque, que incluía autores amigos como Betty Friedan e Alvin Toffler, com quem conversei em cocktail parties diversas vezes em casa. Em Columbia, na residência em que fiquei durante dois anos (Hartley Hall) - contígua à residência onde cinco décadas antes residia o poeta andaluz Federico García Lorca -, partilhei o andar com o filho de Betty Freidan, e com o filho do linguista-antropólogo Dell Hymes, organizador do clássico da antropologia crítica Reinventing Anthropology, de 1969.

2. Uma segunda fase: o choque cultural com a integração no mundo académico britânico, em Colchester, a nordeste de Londres. O meu orientador, Stanley Mitchell - tradutor para inglês da obra The Historical Novel, de Georg Lukàcs (1969 [1937]) - dirigia o seminário de Sociologia da Literatura dedicado a Balzac, Lucien Goldmann e um pós-estruturalismo literário em embrião. Mas, em termos pessoais, foi a primeira vez que vivi críticas ferozes dirigidas contra os Estados Unidos. Para a tese (B. J. O'Neill 1974), recolhi 84 contos populares bilingues numa aldeia da Galiza (na Serra do Caurel, na província de Lugo), tendo sido esta experiência decisiva na escolha de um doutoramento futuro em antropologia. Nesses contos, os animais domésticos (ovelhas e cabras) falavam galego, ao passo que os selvagens (lobos e raposas) falavam castelhano.

3. Um ano mais tarde, em 1973, o ingresso na London School of Economics (LSE), com outro choque de culturas: desta vez, no funcionalismo britânico predominantemente africanista. Lembro-me de ter adormecido na biblioteca, lendo as primeiras páginas de Dynamics of Clanship among the Tallensi, de Meyer Fortes (1945). A antropologia da Índia e do Mediterrâneo eram as correntes contestatárias ao funcionalismo (não havendo ainda nenhuma antropologia da Europa que aglomerasse um conjunto significativo de investigadores). E havia o marxismo estrutural, associado à formação da revista Critique of Anthropology, com a qual mantive uma proximidade. Tive uma cadeira com Maurice Bloch (Antropologia Económica) e um seminário com Ioan Lewis. Na biblioteca do Museum of Mankind, as leituras de Rio de Onor (1953), de Jorge Dias, e de A Portuguese Rural Society (197 1), do meu orientador na LSE, José Cutileiro, foram igualmente decisivas na escolha de Portugal - em vez da Galiza - como local futuro de trabalho de terreno. Mas havia acasos, acontecimentos acidentais. Também ajudou a carta da Fundação Gulbenkian

5 N. O’Neill e G. O’Neill (1972). Logo a seguir, em 1974, publicaram outro livro, que de certa forma foi também uma espécie de "antropologia aplicada”, e que, curiosamente, hoje em dia ganha renovada relevância (devido à crise) com respeito a mudanças de emprego (ver N. O’Neill e G. O’Neill 1974). 
comunicando a concessão de uma bolsa. Poeticamente, fiquei "seduzido" pelo estudo do comunitarismo. E, romanticamente, fiquei atraído pelo primitivismo e atraso do Alto Trás-os-Montes. Adicionalmente, era extremamente atrativo conduzir pesquisa no país, tendo seguido, de Londres, os acontecimentos após o 25 de Abril e ao longo de 1975.

4. Numa terceira fase, de 1976 a 1978, conduzi trabalho de campo em Seixas, no concelho de Vinhais. Entre 1978 e 1982, em Londres, escrevi a tese (defendida em 1982) que viria a ser publicada primeiro em Portugal (B.J. O’Neill 1984). Curiosamente, num pequeno grupo informal de doutorandos, lemos um livro cada quinzena, para dialogarmos sobre as nossas teses. Nesse grupo, lemos Production and Reproduction (1976), de Jack Goody, e Outline of a Theory of Practice (1977 [1972]), de Pierre Bourdieu, ambos tendo sido revelações relativamente aos meus materiais etnográficos transmontanos. Sem a inspiração poética (não só académica) destas duas obras, possivelmente a escrita da tese teria sido muito mais pesada. Julgo, em termos retrospetivos, que valorizei em Bourdieu a vertente quase obcecadamente crítica que o autor tece contra as ortodoxias antropológicas e sociológicas da altura. Não descurando a influência de obras de investigadores britânicos (Peter Laslett, Alan Macfarlane, John Davis), bem como ibéricos (José Cutileiro e Carmelo Lisón-Tolosana). ${ }^{6}$ Também não esqueço os professores de Columbia, bem como as obras de Eric Wolf e Sidney Mintz (ambos colegas do meu pai, e também antigos alunos de Columbia), lidas com interesse mesmo que eu não tivesse estudado diretamente com eles. Após muitas subfases de ambivalência, confusão, dúvidas existenciais, e sentimentos de deslocamento social e mental, o fio condutor da tese tomou forma... As três dimensões confluíam: o académico, o biográfico e o poético.

5. Só mais tarde, após a década que nos ocupa hoje, é que percebi que a escolha da Malásia para um terceiro trabalho de campo talvez se devesse à experiência aos nove anos nas Caraíbas. Foi uma experiência que, quase de modo psicanalítico, permitiu um regresso a um clima e ambiente multiculturais... Também só então, já na década de 1990, é que comecei a refletir sobre a minha própria "assimilação" na sociedade americana. A minha linha materna mais americana subtilmente branqueava alguns tiques hispânicos da linha paterna porto-riquenha e andaluz (a avó paterna era de perto de Córdova). Mas tal consciência "étnica" foi, no meu caso, muito tardia. ${ }^{7}$

6 Veja-se, por exemplo, Laslett e Wall (1972), Macfarlane (1977), Davis (1977), para os primeiros, ou Cutileiro (1971) e Lisón-Tolosana (1966), para os segundos.

7 Viria a saber muito mais tarde que uma prima do meu pai era uma figura destacada na área da psicologia em Porto Rico (A. M. O’Neill 1978). 
Concluindo, será útil aprofundar estas reflexões? Seria interessante refletir mais sobre estas duplas influências nos anos 70, da antropologia norte-americana e britânica, anteriores ao meu contacto com a antropologia portuguesa? Estarei a fabricar, sem sabe-lo, uma espécie de "ilusão biográfica"? Serei um produto híbrido, multinacional? Um crítico literário frustrado, transformado em crítico antropológico? O meu gosto pelo mergulho em detalhe descritivo teria uma origem nas minhas leituras dos grandes romancistas realistas? Sem ser pela via pós-modernista, não será possível combinarmos, com maior intensidade, a etnografia e a literatura ${ }^{8}$ E de forma continuadamente crítica?

Deixo estas reflexões, sem qualquer remorso por ter, biograficamente, entretecido duas, senão mesmo três, identidades distintas...

\section{BIBLIOGRAFIA}

ARENSBERG, Conrad, 1968 [1937], The Irish Countryman: An Anthropological Study. Nova Iorque, The Natural History Press/American Museum of Natural History.

BOURdiEU, Pierre, 1977 [1972], Outline of a Theory of Practice. Cambridge, Cambridge University Press.

CERVANTES SAAVEDRA, Miguel de, 1970 [1605/1615], The Adventures of Don Quixote. Harmondsworth, Penguin (tradução de J.M. Cohen).

CUTILEIRO, José, 1971, A Portuguese Rural Society. Oxford, Clarendon Press.

DAVIS, John, 1977, People of the Mediterranean. Londres, Routledge.

DIAS, António Jorge, 1953, Rio de Onor: Comunitarismo Agro-Pastoril. Porto, Instituto para a Alta Cultura / Centro de Estudos de Etnologia Peninsular.

DOSTOYEVSKY, Fyodor, 1958 [1880], The Brothers Karamazov. Harmondsworth, Penguin, 2 vols. (tradução de David Magarshack).

FORTES, Meyer, 1945, The Dynamics of Clanship among the Tallensi. Londres, Oxford University Press/International African Institute.

FRIED, Morton, 1967, The Evolution of Political Society: An Essay in Political Anthropology. Nova Iorque, Random House.

GLICK-SCHILLER, Nina (col. L. BASCH e C.S. BLANC), 1994, Nations Unbound: Transnational Projects, Postcolonial Predicaments, and Deterritorialized Nation-States. Nova Iorque, Gordon and Breach.

GOODY, Jack, 1976, Production and Reproduction: A Comparative Study of the Domestic Domain. Cambridge, Cambridge University Press.

8 De facto, nalguns textos consegui casar o olhar antropológico com lupas literárias: cf. um artigo dissecando o romance Moby Dick (B. J. O’Neill 1992) através de leituras estruturalistas antropológicas, que teve origem num extenso trabalho de seminário antropológico da licenciatura em Columbia. 
HYMES, Dell (org.), 1969, Reinventing Anthropology. Nova Iorque, Random House.

LASLETT, Peter, col. Richard WALL (orgs.), 1972, Household and Family in Past Time. Londres, Cambridge University Press.

LÉVI-STRAUSS, Claude, 1967 [1955], Tristes Tropiques: An Anthropological Study of Primitive Societies in Brazil. Nova Iorque, Atheneum.

LISÓN-TOlOSANA, Carmelo, 1966, Belmonte de los Caballeros: A Sociological Study of a Spanish Town. Oxford, Clarendon Press.

LUKÁCS, Georg, 1969 [1937], The Historical Novel. Londres, Peregrine Books (tradução de Hannah e Stanley Mitchell).

MACFARlane, Alan, 1977, Reconstructing Historical Communities. Cambridge, Cambridge University Press.

MURPHY, Robert, 1971, The Dialectics of Social Life: Alarms and Excursions in Anthropological Theory. Nova Iorque, Basic Books.

O’NeILl, Ana Maria, 1978, Psicología de la Comunicación. San Juan, Universidad de Puerto Rico.

O’NEILL, Brian Juan, 1974, Oral Literature and Social Change in a Galician Peasant Village. Colchester, University of Essex, Department of Literature, dissertação de mestrado.

O’NEILL, Brian Juan, 1984, Proprietários, Lavradores e Jornaleiras: Desigualdade Social Numa Aldeia Transmontana 1870-1978. Lisboa, Dom Quixote (2. ${ }^{a}$ edição: Porto, Afrontamento, 2011 ; edição em inglês: Social Inequality in a Portuguese Hamlet: Land, Late Marriage, and Bastardy 1870-1978. Cambridge, Cambridge University Press, 1987).

O’NEILL, Brian Juan, 1992, "Un approccio antropologico al 'Moby Dick' di Melville”, em Aurélio Rigoli (org.), Uomini e Culture: Antropologia delle Americhe, vol. I, parte III ("Due mondi a confronto: acculturazione e sincretismi"). Génova, Edizioni Colombo e Comitato Nazionale per le Celebrazioni del V Centenario della Scoperta dell'America, 219-230.

O'NeILl, George Caracena, 1962, Postclassic Ceramic Stratigraphy at Chalco in the Valley of Mexico. Nova Iorque, Columbia University, Faculty of Political Science, Department of Anthropology, tese de doutoramento.

O’NEILL, Nena, e George O'NEILL, 1972, Open Marriage: A New Life Style for Couples. Nova Iorque, M. Evans (2. a edição: 1984).

O’NEILL, Nena, e George O'NEILL, 1974, Shifting Gears: Finding Security in a Changing World. Nova Iorque, M. Evans.

RIEGELHAUPT, Joyce, 1964, In the Shadow of the City: Integration of a Portuguese Village. Nova Iorque, Columbia University, Department of Anthropology, tese de doutoramento (Ann Arbor, Michigan, University Microfilms International, 1982).

SAID, Edward, 1978, Orientalism. Harmondsworth, Penguin.

SARTRE, Jean-Paul, 1943, L'Etre et le Néant. Paris, Gallimard.

SKINNER, B. F., 1953, Science and Human Behavior. Nova Iorque, Macmillan. 